\title{
Right aortic arch with vascular ring in one monozygotic twin
}

\author{
A. Sondakh, MD, ${ }^{a}$ W. Daenen, $M D,{ }^{a}$ M. Gewillig, $\mathrm{MD}, \mathrm{PhD}^{\mathrm{b}}$ K. Devriendt, $\mathrm{MD}, \mathrm{PhD},{ }^{\mathrm{c}}$ and $\mathrm{B}$. Meyns, $\mathrm{MD}, \mathrm{PhD},{ }^{\mathrm{a}}$ \\ Leuven, Belgium
}

$\mathrm{R}$ ight aortic arch (RAA) has been found in approximately $0.1 \%$ of patients. Mostly, RAA is accompanied by cardiovascular congenital anomalies, such as tetralogy of Fallot, pulmonary atresia with ventricular septal defect, and truncus arteriosus. ${ }^{1}$ RAA does not necessarily cause symptoms, but if the clinical manifestations of tracheal and/or esophageal compression are present, then the diagnosis of vascular ring is virtually certain.

Monozygotic twins offer an ideal situation to study the relative contribution of genetics and environment in the development of the cardiovascular system. ${ }^{2}$ We report on monozygotic twins discordant for RAA with vascular ring.

\section{Clinical Summaries}

TWIN 1. As the second child of monochorionic monoamniotic twins, twin 1 was delivered by caesarean section at 31 weeks' gestation because of the deceleration of twin 2. The postnatal period was complicated by pneumothorax and anoxemia. The diagnosis of RAA and ventricle septum defects (5 and $2.7 \mathrm{~mm}$ in diameter) was determined by echocardiography when the patient was 2 weeks old.

She had persistent respiratory symptoms of hyperinflation with airway obstruction. Bronchoscopy showed compression of the distal trachea and left main bronchus.

Barium swallow highlighted an area of extrinsic compression in the mid esophagus posteriorly. The presence of a vascular ring was confirmed by cardiac catheterization (Figures 1 and 2). During surgery, at the age of 9 months, both the retroesophageal ligamentum arteriosum and the atretic distal left arch were divided.

Symptoms improved after surgery. She was discharged on day 4 but was readmitted on day 6 because of a period of apnea due to secondary bronchotracheomalacia. At 7 months' follow-up, she remains symptom free, except for discrete wheezing.

Further clinical examination did not reveal any associated anomalies. The karyotype was a normal $46 \mathrm{XX}$, and any microdeletion in chromosome 22q11 was excluded by means of fluorescence in situ hybridization.

\footnotetext{
From the Departments of Cardiac Surgery, ${ }^{a}$ Paediatric Cardiology, ${ }^{\mathrm{b}}$ and Human Genetics, ${ }^{\mathrm{c}}$ University Hospital Leuven, Leuven, Belgium.

Received for publication Jan 7, 2005; accepted for publication Jan 11, 2005.

Address for reprints: B. Meyns, MD, PhD, Department of Cardiac Surgery, Gasthuisberg University Hospital, Herestraat 49, 3000 Leuven, Belgium (E-mail: Bart.Meyns@uz.kuleuven.ac.be).

J Thorac Cardiovasc Surg 2005;130:883-4

$0022-5223 / \$ 30.00$

Copyright $\odot 2005$ by The American Association for Thoracic Surgery

doi:10.1016/j.jtcvs.2005.01.014
}

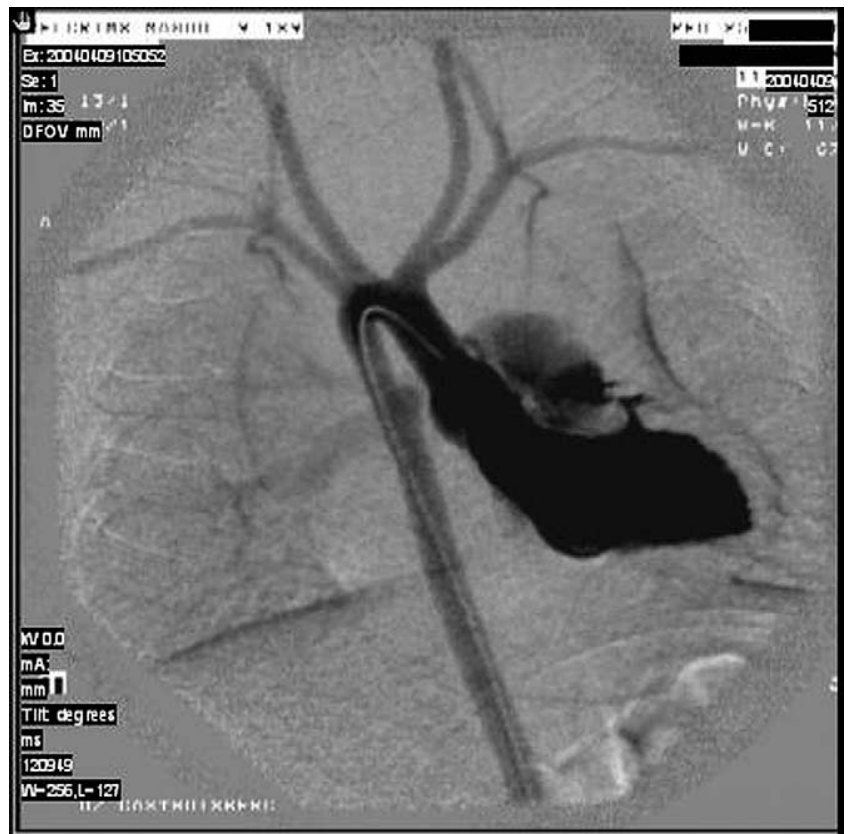

Figure 1. Right aortic arch. The diverticulum of Kommerell at the descending aorta indicates the presence of a left-sided ligamentum arteriosum.

TWIN 2. In twin 2, the delivery and postpartum period were uneventful. Echocardiography was normal.

\section{Discussion}

In 1945, Gross $^{3}$ reported the first surgical repair of double aortic arch. The most common lesion in published series were RAA and left ductus arteriosus (49\% of patients). ${ }^{4}$ The predominance of RAA may be facilitated by flow-related factors in the developing embryo and fetus. Rudolph and colleagues ${ }^{5}$ described in 1972 that the hydrodynamic conditions in the normally developing outflow region of the heart favor the laminar flow of right ventricular output through the left-sided arterial duct and into the left arch. This encourages the predominance of the left arch. With decreased pulmonary outflow in the developing heart, right-to-left ductal flow is absent or diminished, and this allows for a more stochastic distribution of right and left predominance. Lesions with abnormal right ventricular outflow are frequently accompanied by RAA, whether there are deletions of chromosome 22q11 or not. This suggests that deletion is not necessary for the development of RAA in this context. ${ }^{6}$

Twins are known to have an increased incidence of congenital cardiac malformation, but even in monochorionic twins, only 1 


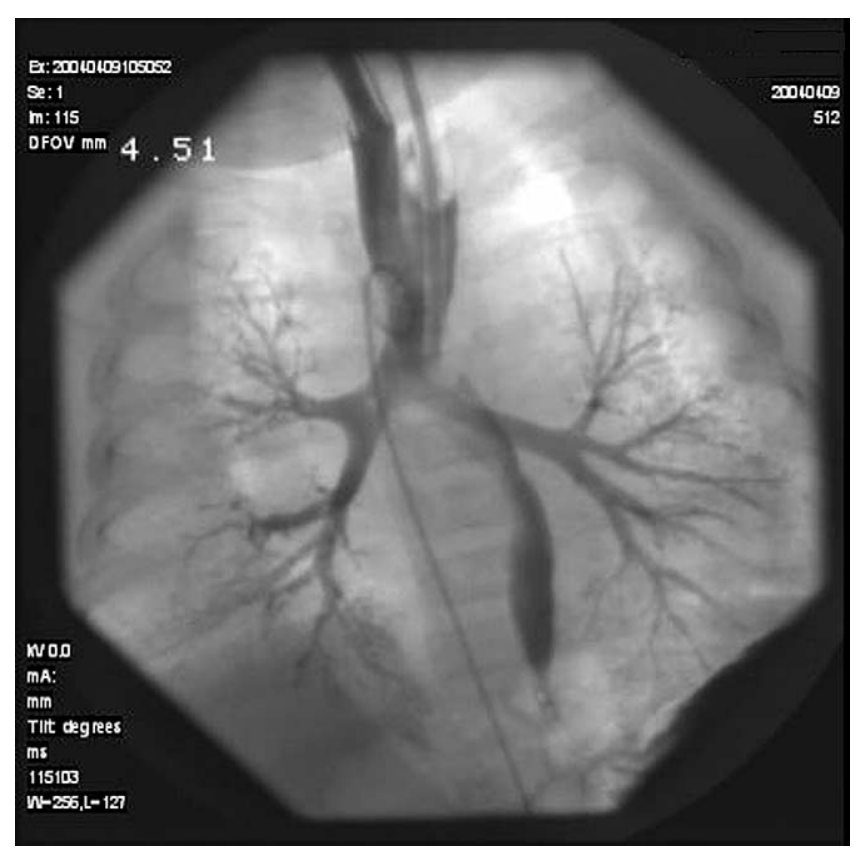

Figure 2. A combination bronchogram/esophagogram during catheterization shows extrinsic compression in the mid esophagus and mild hypoplasia of the proximal part of the left main bronchus.

twin is affected in more than $90 \%$ of cases. The incidence of spontaneous monozygotic twinning is approximately 4 in 1000 live births. Two thirds comprise monochorionic diamniotic twins. Possibly, the monozygotic twinning process itself increases the incidence of congenital heart disease, with postzygotic unequal division of the inner cell mass being responsible for discordant cardiovascular anatomy. Congenital heart defects occur more commonly in monochorionic than in dichorionic monozygotic twins. Monochorionic placentation and its complications may provide a less favorable environment for the developing fetus. The circula- tory imbalance in twin-twin transfusion syndrome augments this increased incidence of congenital heart disease in recipient twins. The influence of the twinning process may thus cause discordant cardiovascular anomalies, including disturbance of laterality and placental vascular anastomoses. ${ }^{2}$

The fact that only 1 of the monozygotic twins had cardiac defects indicates that other nongenetic factors influence cardiac development. Also, the fact that the genotype does not account for all the phenotypic differences implies that we are unlikely to find a genetic explanation for all variations of cardiovascular mispatterning.

There is no controversy about the necessity for surgical management of symptomatic congenital vascular ring. ${ }^{7}$ After surgery, secondary tracheomalacia is mostly present after the prolonged period of airway compression, and symptoms may not resolve completely. Delayed diagnosis of a vascular ring can result in unnecessary investigations and prolonged periods of ineffective treatment.

\section{References}

1. McElhinney DB, Tworetzky W, Hanley FL, Rudolph AM. Congenital obstructive lesions of the right aortic arch. Ann Thorac Surg. 1999;67: 1194-202.

2. Karatza AA, Wolfenden JL, Taylor MJO, Wee L, Fisk NM, Gardiner HM. Influence of twin-twin transfusion syndrome on fetal cardiovascular structure and function: prospective case-control study of 136 monochorionic twin pregnancies. Heart. 2002;88:271-7.

3. Gross RE. Surgical relief for tracheal obstruction from a vascular ring. N Engl J Med. 1945;233:586-90.

4. Kocis KC, Midgley FM, Ruckman RN. Aortic arch complex anomalies: 20-year experience with symptoms, diagnosis, associated cardiac defects, and surgical repair. Pediatr Cardiol. 1997;18:127-32.

5. Rudolph AM, Heymann MA, Spitznas U. Hemodynamic considerations in the development of narrowing of the aorta. Am J Cardiol. 1972;30: 514-25.

6. McElhinney DB, Hoydu AK, Gaynor JW, Spray TL, Goldmuntz E, Weinberg PM. Patterns of right aortic arch and mirror-image branching of the brachiocephalic vessels without associated anomalies. Pediatr Cardiol. 2001;22:285-91.

7. Chun K, Colombani PM, Dudgeon DL, Haller JA Jr. Diagnosis and management of congenital vascular rings: a 22-year experience. Ann Thorac Surg. 1992;53:597-602. 